\title{
ARTE, VERDADE E PESQUISA EM EDUCAÇÃO
}

\author{
ART, TRUTH AND RESEARCH IN EDUCATION
}

ARTE, VERDAD Y INVESTIGACIÓN EN EDUCACIÓN

Luciana Gruppelli Loponte ${ }^{1}$

\section{RESUMO}

O texto pretende apresentar relações entre arte, verdade e pesquisa a partir de discussões filosóficas empreendidas principalmente por Michel Foucault e Friederich Nietzsche, além da reflexão em torno do trabalho de alguns artistas contemporâneos e de seus processos artísticos que desafiam verdades estabelecidas. Tais questionamentos abrem espaço para uma possível abordagem a respeito das emergentes metodologias de pesquisa educacional baseadas em arte. A discussão apresentada dialoga com a experiência de orientação de pesquisas em educação em conversa com o campo das artes, realizadas no âmbito de um programa de pósgraduação em educação.

PALAVRAS-CHAVE: Arte. Verdade. Pesquisa e Educação.

\section{ABSTRACT}

This text aims to present relations between art, truth and research based on philosophical discussions, mainly those by Michel Foucault and Friedrich Nietzsche, as well as reflecting on the works of some contemporary artists and their artistic processes that challenge established truths. This argumentation makes room for a possible approach to emerging educational research methodologies based on art. This discussion dialogues with the experience of supervising educational research in a dialogue with the field of the arts carried out by the a graduate programme in Education.

KEYWORDS: Art. Truth. Research and Education.

\section{RESUMEN}

El texto pretende presentar relaciones entre arte, verdad e investigación a partir de discusiones filosóficas emprendidas principalmente por Michel Foucault y Friederich Nietzsche, además de la reflexión en torno al trabajo de algunos artistas contemporáneos y sus procesos artísticos que desafían verdades establecidas. Tales cuestionamientos abren espacio para un posible abordaje acerca de las metodologías emergentes de investigación educativa basadas en arte. La discusión presentada dialoga con la experiencia de orientación de investigaciones en educación en conversación con el campo de las artes, realizadas en el marco de un programa de postgrado de investigación en educación.

PALABRAS CLAVE: Arte. Verdad. Investigación y Educación

\footnotetext{
${ }^{1}$ Doutora em Educação - Universidade Federal do Rio Grande do Sul (UFRGS) - Porto Alegre, RS - Brasil. Docente - Universidade Federal do Rio Grande do Sul (UFRGS) - Porto Alegre, RS - Brasil. E-mail: luciana.loponte@ufrgs.br Submetido em: 09/01/2018 - Aceito em: 06/12/2018.
}

(C) ETD-Educação Temática Digital Campinas, SP $\quad$ v.21 $\quad$ n.2 $\quad$ p. 479-494 abr./jun.2019


No descomeço era o verbo.

Só depois é que veio o delírio do verbo. O delírio do verbo estava no começo, lá onde a criança diz: eu escuto a cor dos passarinhos. A criança não sabe que o verbo escutar não funciona para cor, mas para som. Então se a criança muda a função de um verbo, ele delira. E pois. Em poesia que é voz de poeta, que é a voz de fazer nascimentos O verbo tem que pegar delírio. (Manoel de Barros - O livro das ignorãças)

A poesia de Manoel de Barros é, sem dúvida, inspiradora. Mais do que uma bela epígrafe, a poesia dele não abre este texto por acaso, e é um mote para uma discussão filosófica que envolve arte, verdade e pesquisa. Esquecemos que as palavras e a verdade a elas associadas são nada mais do que metáforas, como nos alertava Nietzsche muitos anos atrás: "Acreditamos saber algo das coisas mesmas, se falamos de árvores, cores, neve e flores, e, no entanto, não possuímos nada mais do que metáforas das coisas, que de nenhum modo correspondem às entidades de origem" (NIETZSCHE, 2014, p. 65). Manoel de Barros reivindica que o verbo ou a palavra também sejam capazes de delirar, tal como uma criança que acredita que pode "escutar a cor dos passarinhos". Nossos verbos, nossas palavras deixaram de delirar há muito tempo. Como adultos, do alto da nossa racionalidade e cheios das certezas do mundo, achamos graça das palavras inventadas pelas crianças e, muitas vezes, vemos nas invenções de poetas e artistas algo talvez próximo da loucura ou da pura inutilidade (ORDINE, 2016). O tempo passa, a dureza da verdade da vida nos assola, e esquecemos que um dia inventávamos, que também delirávamos, que fazíamos nascimentos.

Associo essas questões aos modos com os quais produzimos conhecimento no âmbito da pesquisa em educação. Essa discussão parte da minha experiência como pesquisadora e orientadora de outras pesquisas em educação em conversa com o campo das artes. Nessa direção, este texto pretende apresentar relações entre arte, verdade e pesquisa a partir de discussões filosóficas empreendidas principalmente por Michel Foucault e Friederich Nietzsche, abrindo espaço para uma possível abordagem a respeito das emergentes metodologias de pesquisa educacional baseadas em arte. Na esteira dessa discussão, apresento algumas experimentações investigativas que temos feito no âmbito de um programa de pós-graduação em pesquisa em educação.

$\begin{array}{llllll}\text { (c) ETD-Educação Temática Digital } & \text { Campinas, SP } & \text { v.21 } & \text { n.2 } & \text { p. 479-494 } & \text { abr./jun.2019 }\end{array}$ 


\title{
1 ARTE E AS HETEROTOPIAS DA PESQUISA
}

Para quê, afinal, pesquisamos? Ou, mais precisamente, por que pesquisamos em educação? O campo da educação do Brasil - cheio de fraturas que envolvem a situação de escolas, de docentes, de alunos, de políticas educacionais e que também inclui precariedades materiais e epistemológicas, bem como questões referentes a currículos e a metodologias e tantas outras questões - constitui-se como um campo minado, aberto e complexo para problematizações. Em meio a essa trama complexa, elegi perseguir as relações entre arte e educação ou, mais precisamente, arte e docência (LOPONTE, 2012, 2013, 2017). Instigada por um pensamento filosófico que continuamente me faz duvidar de meu próprio pensamento, invento novas relações entre o que se compreende por arte e o que pode ser entendido por educação ou docência. Rejeito uma relação fixa e estável entre esses conceitos, provocando novos arranjos ou pontos de vista inusitados ou não trilhados. Prefiro ${ }^{2}$ as heterotopias que inquietam, às utopias que consolam.

As utopias, diz Foucault, são consoladoras, nos prometem um não lugar onde tudo se realiza, um "espaço maravilhoso e liso", no qual as cidades têm "vastas avenidas, jardins bem plantados, regiões fáceis" (FOUCAULT, 2012, p. XIII). Nesse lugar chamado utopia, teríamos um corpo "belo, límpido, transparente, luminoso, veloz, colossal na sua potência, infinito na sua duração, solto, invisível, protegido, sempre transfigurado" (FOUCAULT, 2013, p. 8). Por outro lado, as heterotopias:

\begin{abstract}
As heterotopias inquietam, sem dúvida porque solapam secretamente a linguagem, porque impedem de nomear isto e aquilo, porque fracionam os nomes comuns ou os emaranham, porque arruínam de antemão a 'sintaxe', e não somente aquela que constrói as frases - aquela, menos manifesta, que autoriza 'manter juntos' (ao lado e em frente umas das outras) as palavras e as coisas. Eis por que as utopias permitem as fábulas e os discursos: situam-se na linha reta da linguagem, na dimensão fundamental da fábula; as heterotopias (encontradas tão frequentemente em Borges) dissecam o propósito, estancam as palavras nelas próprias, contestam, desde a raiz, toda possibilidade de gramática; desfazem os mitos e imprimem esterilidade ao lirismo das frases (FOUCAULT, 2012, p. XIII).
\end{abstract}

Fracionar conceitos, emanharar sentidos, deslocar a linha reta da linguagem que une arte e educação, tem sido um dos meus propósitos como pesquisadora. Escapar do doce gosto das avenidas ensolaradas já trilhadas nem sempre é uma aventura fácil. As utopias e suas promessas de redenção são sedutoras e não nos deixam em paz. No entanto, pensar as

\footnotetext{
${ }^{2}$ A opção pela primeira pessoa aqui revela uma implicação pessoal e subjetiva com as questões aqui analisadas que, no entanto, não é solitária. Trata-se de uma singularidade povoada por vários parceiros, como meus orientandos de graduação, mestrado e doutorado nos últimos anos na Faculdade de Educação da Universidade Federal do Rio Grande do Sul.
}

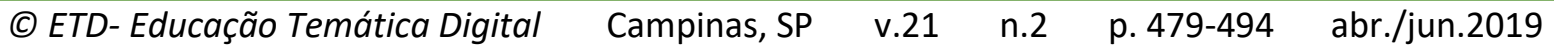


heterotopias de uma pesquisa, esse contraespaço de pensamento, pode ser mais instigante. Foucault sonhava com uma ciência que "teria por objeto esses espaços diferentes, esses outros lugares, essas contestações míticas e reais do espaço em que vivemos" (FOUCAULT, 2013, p. 21). Essa ciência nomeada pelo filósofo de "heterotopologia", caso precisemos de um nome, estudaria esses espaços outros. Talvez a questão para nós seja não uma outra ciência, mas a produção de contraespaços nos nossos próprios modos de investigação, estes que carregam o peso dos burocráticos métodos científicos e da busca por verdades irrefutáveis.

Gallo toma o conceito de heterotopias de Foucault de forma admirável para pensar a escola, aceitando o convite de "pensar de outros modos: a possibilidade de fazer uma escola outra na escola estabelecida" (GALLO, 2015, p. 442). Muito mais do que utopias pedagógicas, essas que inflacionam os discursos educacionais e inflamam discursos políticos, a reivindicação é pensar nas "heterotopias pedagógicas", a "produção cotidiana de escolas outras, lá, no interior da escola mesma" (GALLO, 2015, p. 442). É um olhar atento para o que acontece na escola nos seus interstícios e intervalos disciplinares, nos espaços não escrutinados pela rotina escolar, na invenção de outros espaços ali mesmo, naquele lugar em que parece que já se fez e se disse tudo o que era possível dizer e fazer.

É instigante pensar as heterotopias a partir de exemplos trazidos pelo próprio Foucault, contraespaços que as crianças conheceriam tão bem: o fundo de um jardim ou a "grande cama dos pais em uma quinta-feira à tarde":

É nessa grande cama que se descobre o oceano, pois nela se pode nadar entre as cobertas; depois, essa grande cama é também o céu, pois se pode saltar sobre as molas; é a floresta, pois pode-se nela esconder-se; é a noite, pois ali se pode virar fantasma entre os lençóis; é, enfim, o prazer, pois no retorno dos pais, se será punido (FOUCAULT, 2013, p. 20).

Uma cama-oceano, uma cama-céu, uma cama-floresta, uma cama-fantasma: pura poesia, invenção, transgressão. Arte? É dessas transgressões da linguagem e de produção de espaços outros de que se alimentam poetas e escritores como Manoel de Barros e Jorge Luis Borges. Assim como artistas visuais como Jonathas de Andrade, Rosana Paulino e Joan Fontcuberta. E aqui volto a um dos argumentos principais desse artigo: o que nossas pesquisas sobre educação podem aprender com esses artistas e suas verdades inventadas?

Na série "Educação para adultos", o artista Jonathas de Andrade se apropria de 20 cartazes educacionais impressos na década de 70 , utilizados por sua mãe no âmbito do método Paulo Freire de alfabetização ${ }^{3}$. A partir desses cartazes, o artista realiza encontros

\footnotetext{
${ }^{3}$ Mais informações sobre este trabalho no site: http://cargocollective.com/jonathasdeandrade/educacao-paraadultos
}

(C) ETD-Educação Temática Digital Campinas, SP $\quad$ v.21 $\quad$ n.2 $\quad$ p. 479-494 abr./jun.2019 
diários com um grupo de analfabetas durante um mês. Desses encontros, emergiram conversas que geravam uma pauta fotográfica para criação de novos cartazes. Tais cartazes voltavam para a conversa, gerando o que o artista chamou de "engrenagem artísticoeducacional".

A coleção final criada pelo artista descola-se da coleção original, podendo ser recriada a partir do repertório do espectador. Nesta engrenagem inventada pelo artista, ora ele se posiciona como educador, ora como um pesquisador do cotidiano, ora como artista ou etnógrafo. Nesse lugar "heterotópico", ele não quer exatamente localizar-se, filiar-se a uma identidade predeterminada:

A arte me permite experiências que seriam impossíveis enquanto somente pesquisador ou cientista social. Posso manejar tradições com mais fluidez; inventar metodologias; experimentar ficções em que posso ser ora pedagogo e pesquisador, ora fugitivo, extraditado, meliante. Parto de urgências e desconfortos cotidianos, de certa forma até pessoais, que ganham dimensão social através da experiência artística. Com isso me torno como uma célula geracional e o percurso do trabalho detona uma série de contradições que me colocam diretamente em contato com o tempo que me precede, fazendo da História, da Economia e dos Problemas Nacionais entidades mais palpáveis, menos abstratas. ${ }^{4}$

A artista Rosana Paulino, desafia o discurso científico de um zoólogo suíço que, em meados do séc. XIX, esteve em expedição no Brasil para provar a superioridade da etnia branca, condenando qualquer miscigenação étnica e racial. Imagens fotográficas derivadas desse projeto, agora em domínio público, produzem um retrato da população escrava do período no Rio de Janeiro. A artista apropria-se dessas imagens que, com um caráter "científico", registram pessoas negras de frente, de lado e de costas. Na série "Assentamento", a artista dá nova vida aos corpos femininos negros anônimos, fazendo-os nascer novamente, iluminados pela sua intervenção em forma de desenhos, bordados, novas linhas ${ }^{5}$.

O artista Joan Fontcuberta cria vários projetos em que desafia os limites entre realidade e ficção. Em uma de suas séries fotográficas memoráveis, "Fauna", cria narrativas visuais de uma suposta expedição científica do passado em que teriam sido descobertos animais inusitados. As fotos, juntamente com mapas, desenhos, radiografias e documentos, recriam todos os aparatos de um suposto achado científico. O cientista de jaleco branco observando os animais e o amarelado das fotos conferem um tom de "verdade" a algumas narrativas. Um dos motes inspiradores do trabalho foi uma frase do ganhador do Nobel da

\footnotetext{
${ }^{4}$ Jonathas de Andrade. Disponível em: http://cargocollective.com/jonathasdeandrade/educacao-para-adultos Acesso em 08 de dezembro de 2017.

${ }^{5}$ Outras informações sobre a série "Assentamentos" e a artista em: http://www.rosanapaulino.com.br/projetos/
}

(C) ETD-Educação Temática Digital Campinas, SP $\quad$ v.21 $\quad$ n.2 $\quad$ p.479-494 abr./jun.2019 
Medicina em 1965, François Jacob: "O existente só é apenas uma parte do possível”6. Joan Fontcuberta assume que mente quando fotografa e chama atenção para que toda e qualquer fotografia ou mesmo qualquer imagem, por mais desejo de verdade que contenha, é pura ficção:

Toda fotografia é uma ficção que se apresenta como verdadeira. Contra o que nos inculcaram, contra o que costumamos pensar, a fotografia mente sempre, mente por instinto, mente porque sua natureza não lhe permite fazer outra coisa. Contudo, o importante não é essa mentira inevitável, mas como o fotógrafo a utiliza, a que propósitos serve. 0 importante, em suma, é o controle exercido pelo fotógrafo para impor um sentido ético à sua mentira. $\mathrm{O}$ bom fotógrafo é o que mente bem a verdade (FONTCUBERTA, 2010, p. 13)

Esses três artistas são alguns entre tantos que desafiam verdades de discursos educacionais, discursos raciais e étnicos, discursos científicos por meio da arte, recriando novas relações entre imagens, palavras e coisas e ocupando um lugar intersticial que não é nem de um educador ou de um cientista, ou de uma etnógrafa, ou muito menos de alguém que quer descobrir a verdade sobre o que quer que seja. Tal como Nietzsche, eles intuem através de suas produções artísticas que as verdades "são ilusões; das quais se esqueceu que o são, metáforas que se tornaram gastas e sem força sensível, moedas que perderam sua efígie e agora só entram em consideração como metal, não mais como moedas" (NIETZSCHE, 2014, p. 66).

Há muito a aprender com essa atitude diante do mundo: uma outra posição diante da verdade, uma abertura à experimentação, uma descrença a protocolos já predeterminados e colados a uma certa tradição disciplinar e científica. Há aqui, menos uma "vontade de verdade", de uma ansiedade de saber a verdade a todo custo, e mais uma "vontade de criação" que, no caso desses artistas, não está desencarnada de uma atitude ética e política. Como pesquisadores, embebidos de uma certa razão científica, acreditamos que nossas investigações que seguirem determinadas regras metodológicas, que legitimarem a validade de nossas incursões em direção ao conhecimento, nos levarão à verdade. Doce ilusão, já bradava Nietzsche, há muitos anos, como salienta Machado (2002, p. 75): "A vontade de verdade é a crença, que funda a ciência, de que nada é mais necessário do que o verdadeiro. Necessidade não de que algo seja verdadeiro, mas de que seja tido como verdadeiro. A questão não é propriamente a essência da verdade, mas a crença na verdade".

A crença desenfreada na verdade e a crença que a ciência e o conhecimento nos possibilitarão, enfim, chegar à verdade das coisas, nos fez esquecer o caráter inventivo e metafórico da relação entre as palavras (os conceitos, os conhecimentos construídos e

\footnotetext{
${ }^{6}$ Mais informações sobre a série "Fauna" e o trabalho do artista em https://www.fontcuberta.com/. Acesso em: 08 dez de 2017.
}

(C) ETD-Educação Temática Digital Campinas, SP $\quad$ v.21 $\quad$ n.2 $\quad$ p. 479-494 abr./jun.2019 
estabelecidos) e as coisas do mundo (nossos objetos de pesquisa, por exemplo). Esquecemos que os verbos deliram, que os jardins podem ser espaços mágicos, que uma grande cama pode ser um oceano incrível, que uma escola pode ser mais do que um espaço disciplinar de reclusão, que uma pesquisa pode fazer mais do que confirmar uma verdade que já se sabe. Cegos pela vontade de verdade do conhecimento e da ciência, esquecemos milenarmente que os conhecimentos nos quais baseamos a nossa vida e nossa atuação no mundo, não passam de uma invenção. Nietzsche, com sua fina ironia, nos alerta:

Em algum remoto rincão do universo cintilante que se derrama em um sem número de sistemas solares, havia uma vez um astro, em que animais inteligentes inventaram o conhecimento. Foi o minuto mais soberbo e mais mentiroso da "história universal": mas também foi somente um minuto. Passados poucos fôlegos da natureza congelou-se o astro, e os animais inteligentes tiveram de morrer (NIETZSCHE, 2014, §1, p.62).

Ressaltar o caráter inventivo do conhecimento não quer dizer que vivemos em um mundo de mentiras e que em algum momento seremos despertados de um sonho ruim. Reconhecer que o conhecimento é abastecido por metáforas que associam arbitrariamente determinadas palavras e conceitos às coisas, nos reaproxima da arte e da criação, tão desvalorizada secularmente pela racionalidade da civilização ocidental. Nietzsche nos instiga não apenas a questionar as verdades, mas também o valor que damos às verdades cristalizadas como "conhecimentos universais" ou como "ciência". O que se busca, enfim, é "reinstaurar a capacidade criativa e, portanto, móvel dos valores" (MOSÉ, 2005, p.71). Quando nomeamos algo, quando fixamos um determinado sentido a um objeto ou pessoa ou ação, mascaramos e escondemos a pluralidade que lhe deu origem. Quando, por exemplo, associamos e fixamos determinadas condutas de pesquisa ou metodologias ou abordagens à relação entre arte e educação, acabamos nos distanciando de inúmeras outras possibilidades. Se, por um lado, necessitamos de certos acordos de linguagem para vivermos em sociedade, por outro lado, podemos questionar o valor que damos às palavras e aos conceitos, às verdades que nos regem, que aprisionam, que se fixam em sentidos que não ousamos duvidar. É nesse sentido que a arte é tão central para a crítica que Nietzsche faz à crença na verdade, não propriamente a arte feita pelos artistas (que muitas vezes o enfadava), mas "uma atividade propriamente criadora, uma força artística presente não somente nos homens, mas em todas as coisas" (MOSÉ, 2005, p. 79). A verdade, essa verdade verdadeira tão buscada pela ciência, pelos critérios de validade e legitimação científica, esconde de si mesma (e de nós, seus fiéis seguidores) seu potencial artístico: “A verdade é uma ilusão que não quer explicitar que é ilusão, então a verdade é uma 'mentira'. Já a arte 'trata a aparência como aparência, não quer, pois, enganar, é verdadeira'. A verdade é um tipo de arte que esconde as condições de seu nascimento" (MOSÉ, 2005, p. 82).

Artistas (ou, para não generalizar, alguns deles) através de suas produções que se aproximam despretensiosamente ou não das verdades do mundo, escancaram o caráter

$\begin{array}{llllll}\text { (C) ETD- Educação Temática Digital } & \text { Campinas, SP } & \text { v.21 } & \text { n.2 } & \text { p.479-494 } & \text { abr./jun.2019 }\end{array}$


inventivo da nossa relação com as coisas, experimentando novos pontos de partida para o pensamento, ensaiando respostas às diferentes problemáticas, propondo não simplesmente soluções que nos tragam sínteses confortáveis, mas que abram novas trilhas e modos de pensar. São artistas como esses que têm alimentado as pesquisas do grupo ARTEVERSA Grupo de estudo e pesquisa em arte e docência (UFRGS/CNPq) e que também são apresentados e compartilhados como nossa "coleção de exemplos" (DE DUVE, 2009) no site homônimo (www.ufrgs.br/arteversa). Para De Duve, a arte é mais do que um conceito, mas uma "coleção de exemplos" (DE DUVE, 2009, p. 51), que pode ser diferente para cada um. Tomamos essa noção para formarmos a nossa própria coleção, destacando obras e artistas que tem nos instigado a pensar não apenas sobre as possibilidades da própria arte contemporânea, mas sobre docência e formação. Entendemos que algumas produções artísticas encarnam, de alguma maneira, um modo estético de estar e atuar no mundo e de se posicionar sobre os problemas que nos assolam, encarnam uma atitude estética diante da vida, um compromisso político e ético com uma "vida não-fascista" (FOUCAULT, 2004), instigando novos modos de criar a nós mesmos e nossas práticas pedagógicas (FISCHER, 2016). Artistas como Luís Camnitzer, Cinthia Marcelle, Valeriano López entre outros, nos dão alguns exemplos de como inquietações sobre a educação podem transformar-se em produções artísticas.

O que nossas pesquisas e inquietações pedagógicas que escolhem enfrentar as complexas problemáticas que envolvem a educação e, em especial, a docência, podem aprender com essa atitude artista diante das coisas? Voltando a Nietzsche e seu memorável aforismo "O que devemos aprender com os artistas" (NIETZSCHE, 2001, §299, p. 202), podemos aprender a sermos "poetas-autores de nossas vidas". Poesia e autoria tem a ver com criação, com invenção de novas relações para os esquemas de pensamento com os quais nos acostumamos a lidar sobre as verdades do mundo. Podemos aprender que a arte, esta ação humana obscurecida como ornamento, afetação e falta de seriedade, é mais do que uma necessidade, faz parte da nossa sobrevivência:

Ao contrário da verdade, da identidade, do ser, o que se encontra no nascimento de todas as coisas é a necessidade de ficção, de ilusão, de arte. Se o intelecto é fundamental para a sobrevivência do homem, a arte, como capacidade de invenção, é igualmente necessária para esta mesma sobrevivência. No entanto, foi o esquecimento da necessidade estética do homem a condição para o exercício da crença na verdade: para que o homem acreditasse na verdade de suas construções, de seus signos, foi preciso que esquecesse de si mesmo 'como sujeito da criação artística' (MOSÉ, 2005, p. 83). (grifos meus).

Nós, sujeitos da criação artística, nós, artistas do conhecimento, da palavra, do cotidiano, da pesquisa, da escola, da docência. Por que não? Nós, homens e mulheres sérios, racionais, crentes no poder do conhecimento e da verdade, simplesmente esquecemos milenarmente, secularmente como civilização ocidental - que somos também,

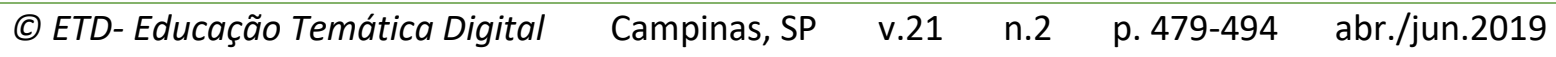


inerentemente, seres criadores. $E$, ajustando o foco para dar um close nas aulas de arte que temos produzido em escolas da educação básica pelo Brasil afora, nem elas têm sido capazes de nos lembrar?.

Nessa direção, que movimentos temos feito e experimentado em nossas pesquisas?

\section{EXPERIMENTAÇÕES INVESTIGATIVAS: ARTE E PESQUISA EM EDUCAÇÃO}

Nossas investigações e metodologias utilizadas não estão descoladas das escolhas teóricas que as embasam. Se, a partir de Foucault e Nietzsche, duvidamos das verdades cristalizadas, enfatizando uma postura antiessencialista e anti-fundacionista na produção de conhecimento, é esta postura que adotamos ao longo de nossas investigações. Ao tomar essa posição investigativa e contaminarmos a produção derivada com certa abertura e fluidez de pensamento, não abrimos mão do rigor e da consistência teórica. O movimento a ser feito nas análises sobre aproximações e tensões entre arte, educação e docência nos faz desconfiar de algumas certezas ligadas ao que se tem dito sobre o que significa ser docente em tempos contemporâneos e sua relação com a arte, por exemplo. Ou ainda, nos faz indagar e analisar os movimentos que artistas e curadores ao redor do mundo têm feito em direção à educação, pensando nas apropriações e interpretações que tem sido feitas. A atitude investigativa adotada aqui, especialmente inspirada em Foucault, é uma atitude de entrega "a modos de pensamento que aceitem o inesperado, especialmente aquilo que se diferencia do que ele próprio pensa" (FISCHER, 2012, p. 100). Procuramos estar atentos às contradições dos discursos, a complexidade das questões levantadas, às relações inusitadas e impensadas que podemos fazer entre arte, educação e docência:

O convite que o pensamento foucaultiano nos faz é o de imergir nesses ditos que se cristalizam e buscar descrever - tanto no interior das próprias pesquisas já feitas sobre o tema quanto numa nova proposta de estudo empírico - práticas discursivas e práticas não discursivas em jogo; o objetivo é que, de tal modo, possamos fazer aparecer justamente a multiplicidade e a complexidade dos fatos e das coisas ditas, que são, por isso mesmo, raros, no sentido de que não são óbvios, não são naturais, não estão imunes a imprevisibilidades. Expor essas multiplicidades nos permitirá descrever um pouco dos regimes de verdade de uma certa formação histórica e de determinados campos de saber (FISCHER, 2012, p.103).

\footnotetext{
${ }^{7}$ Nesse contexto, é muito preocupante as ações cada vez mais amplas realizadas pelo chamado movimento "Escola sem Partido" que pretende, a partir de interferências na legislação brasileira, criminalizar e amordaçar o pensamento próprio e autônomo de docentes em nome do que chamam de "neutralidade da educação" ou do combate a uma certa "doutrinação política" que seria empreendida por professores adeptos às teorias de Paulo Freire, por exemplo. Em 2017, testemunhamos também um intenso ataque a exposições de arte a partir de acusações moralistas envolvendo sexualidade e infância (ver Dossiê Arte sob coerção: moralismo privado no espaço público, Revista Cult, dezembro 2017).
}

(C) ETD-Educação Temática Digital Campinas, SP $\quad$ v.21 $\quad$ n.2 $\quad$ p.479-494 abr./jun.2019 
Destaca-se que "pensar diferente do que se pensa" requer atenção e rigor, e não um relativismo que possa nos paralisar. Assumimos uma postura de pensamento capaz de duvidar de nossas crenças mais arraigadas sobre o que pode significar a docência e sua formação ligada às artes. A complexidade da docência, envolvendo a educação básica hoje, exige que pensemos a partir de pressupostos não tradicionais, experimentando outras formas de pensar sobre educação ou, mais especificamente, sobre as relações possíveis entre arte e docência. Como Foucault, somos instigados pela curiosidade, assumindo "o descaminho de quem conhece" e os riscos daí derivados:

Quanto àqueles para quem esforçar-se, começar e recomeçar, experimentar, enganar-se, retomar tudo de cima a baixo e ainda encontrar meios de hesitar a cada passo, àqueles para quem, em suma, trabalhar mantendo-se em reserva e inquietação equivale à demissão, pois bem, é evidente que não somos do mesmo planeta (FOUCAULT, 1998, p.12).

O desejo de habitar a docência (seus conceitos, efeitos e práticas) a partir de processos e práticas artísticas contemporâneas e de uma formação que não prescinda de uma atitude estética é um dos principais movimentos teóricos e metodológicos que temos feito ${ }^{8}$.

Além das perspectivas teóricas já mencionadas, entendemos que a aproximação com práticas artísticas contemporâneas para pensar a docência também contamina nossos modos de pesquisar. Algumas atitudes em relação ao conhecimento e aos objetos de pesquisa são semelhantes àquelas utilizadas por artistas contemporâneos no uso do mundo como repertório de formas à sua disposição (BOURRIAUD, 2009). É nesse sentido que temos nos aproximado, de modo mais contundente e a partir de um olhar crítico e criterioso, sem uma adesão tácita, das chamadas "investigações baseadas em arte", desenvolvidas há pouco tempo no Brasil e também em países como Estados Unidos, Canadá e Espanha (DIAS, 2013; HERNÁNDEZ, 2013; JAGODZINSKI, WALLIN, 2013; MARTINS, TOURINHO, 2013; ROLDÁN, VIADEL, 2012; VIADEL, 2006). A nossa aproximação com este tipo de pesquisa é acentuada, mas também desconfiada, em uma atitude menos colonial ou submissa a modelos estrangeiros e mais propositiva.

Se a investigação dita como "científica" é marcada historicamente pela dualidade, como a distinção e separação entre sujeito e objeto, as metodologias de pesquisa que se baseiam em arte rompem com as dicotomias, propondo que existem outros modos de conhecer que, juntamente com os modos considerados estritamente "científicos" podem contribuir para pensar a respeito de problemas humanos e sociais e, inclusive, os problemas

\footnotetext{
${ }^{8}$ Este é um dos movimentos gerados pela pesquisa "Docência como campo expandido: arte contemporânea e formação estética" (financiada pelo CNPq de 2013 a 2016) e na continuidade da investigação "O campo expandido da arte e da docência: aproximações, tensões e processos e práticas artísticas contemporâneas" (Início em 2016, em andamento).
}

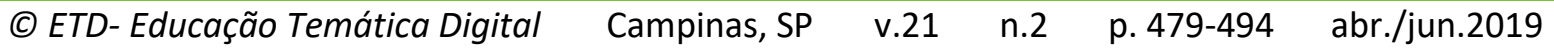


educativos. Como aponta Viadel (2012), a ideia chave das Metodologias Artísticas de Pesquisa é simples: "aproveitar as artes para fazer investigação":

Por que usar as artes para fazer pesquisa é uma arriscada e chamativa novidade? Porque a criação artística e a pesquisa científica são campos de conhecimento que são muito especializados e historicamente foram rotundamente diferenciados. A formação de seus respectivos profissionais, a dinâmica de trabalho das equipes científicas e dos grupos artísticos, o funcionamento das instituições científicas e das artísticas, os foros de encontros profissionais, sejam congressos, concursos, eventos ou bienais, e os critérios, normas e regras para avaliar os resultados obtidos, são completamente distintos para as artes e para as ciências. De forma talvez demasiado taxativa, habitualmente se diferencia entre a objetividade, exatidão e rigor da ciência, e a liberdade e subjetividade das artes. Por isso, quando unimos os termos 'arte' e 'pesquisa' parece que estamos forçando o sentido estrito das palavras (tradução nossa). (ROLDÁN, VIADEL, 2012, p. 25-26).

Contaminados com essas e outras indagações de cunho mais filosófico, é que pautamos nossas investigações, tendo a arte tanto como objeto de nossas preocupações em relação à educação, em especial com a formação docente, quanto como modo de olhar e pensar ou como "plataforma" da qual partem nossas inquietações. Tomo a ideia de "arte como plataforma de pensar" a partir de Canclini (2012) e de sua apropriação das obras do artista Gabriel Orozco. Para Canclini, na contramão de se pensar na arte como um saber oposto à racionalidade científica ou como mera ilustração de ideias políticas ou filosóficas, é possível pensar em artistas que "apresentam-se como pesquisadores e pensadores que desafiam, em seus trabalhos, os consensos antropológicos e filosóficos sobre as ordens sociais, sobre as redes de comunicação ou os vínculos entre indivíduos e seus modos de se agrupar" (CANCLINI, 2012, p. 50).

Antes da emergência de um tipo de investigação que tenha a arte como um de seus pressupostos, já aprendemos com Nietzsche o quanto esquecemos milenarmente do nosso impulso inventivo, da nossa capacidade de metaforizar o mundo, e que é na arte que podemos encontrar território para abrigar nossa vontade de criação:

Esse impulso à formação de metáforas, esse impulso fundamental do homem, que não se pode deixar de levar em conta nem por um instante, porque com isso o homem mesmo não seria levado em conta, quando se constrói para ele, a partir de suas criaturas liquefeitas, os conceitos, um novo mundo regular e rígido como uma praça forte, nem por isso, na verdade, ele é subjugado e mal é refreado. Ele procura um novo território para sua atuação e um outro leito de rio, e o encontra no mito e, em geral, na arte. (NIETZSCHE, 2014, §2, p. 68).

Como docentes e pesquisadores, ao esquecermos da nossa necessidade estética de relação com o mundo, para acreditarmos nas verdades eternas e imutáveis que aprendemos a chamar de "conhecimento", além de esquecermos de nós mesmos como "sujeitos da criação artística" (MOSÉ, 2005, p. 83), passamos a "limitar a linguagem a figurar e representar" (MARTON, 2010, p. 132). A tarefa de crítica da vontade conservadora da

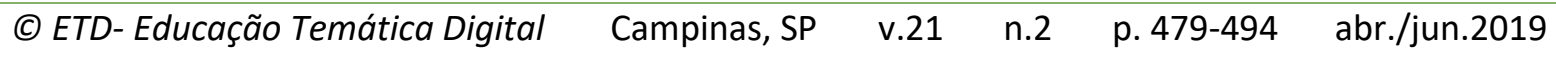


linguagem é tomada por Nietzsche em seus próprios textos - aforismos, poemas, palavras ressignificadas - lançando mão de vários recursos para atrair seus leitores, provocá-los, instigá-los, fazê-los levantar de suas confortáveis cadeiras. Além da contundente crítica, "mais do que um pensador que se debate nas redes da linguagem, Nietzsche é o filósofo que a faz voltar-se contra si mesma - para criar uma nova linguagem. Como Freud, ele está em busca de palavras para o seu próprio indizível" (MARTON, 2010, p. 142).

Quais as palavras e imagens para o indizível de nossas pesquisas em educação? Que novas formas, que "novas liras" teremos que inventar para tratar das questões que nos inquietam e que não cabem na linguagem pretensamente "verdadeira" e "científica"?

Quase como uma resposta ao apelo nietzschiano pelo nosso impulso metafórico e artístico, alguns movimentos relacionados com a arte contemporânea têm procurado dialogar com a complexidade da sociedade em que vivemos, esgarçando as fronteiras entre arte e ciência, verdade e ficção. É o caso da proposta da Bienal de São Paulo, realizada de setembro a dezembro de 2016. Com o mote de "Incerteza Viva", a curadoria instigou, através de sua proposta, que não tenhamos medo da incerteza, utilizando-a para refletir sobre as nossas condições de vida:

\begin{abstract}
Diferentemente do que acontece em outros campos de pesquisa, a incerteza na arte aponta para a criação, levando em conta a ambiguidade e a contradição. A arte se alimenta de incerteza, do acaso, da improvisação, da especulação e do acontecimento. Muitas vezes a arte se põe a medir o imensurável. Ela abre passagem para o erro, a dúvida e até para os mais profundos receios, sem fugir deles nem os manipular. (...) A arte promove um intercâmbio ativo entre pessoas, reconhecendo as incertezas como sistemas de orientação geradores e construtivos. Logo, não faria sentido tomar os inúmeros métodos de raciocinar e de fazer arte e aplica-los a outros campos da vida pública?" (VOLZ, 2016, p. 25. Grifos meus)
\end{abstract}

A pergunta de Volz (associada com as provocações nietzscheanas) reverbera nas nossas inquietações em relação à pesquisa em educação. Nos últimos anos, no âmbito do Programa de Pós-Graduação e Pesquisa em Educação da UFRGS e do grupo ARTEVERSA, temos realizado algumas experimentações em algumas recentes pesquisas (FISCHER, 2014; STORCK, 2015; COSTA, 2015; BELLO, 2016; BREMM, 2017; CAPRA, 2017). Aproximação entre professoras e artistas em um ambiente de aprendizado mútuo em uma escola; produções artísticas que tematizam de modo inusitado as experiências escolares ou inspiram um olhar diferenciado para a escola e seus processos pedagógicos; aproximação entre crianças de dois países latino-americanos através de diálogos fotográficos no âmbito de espaços extracurriculares; residências artísticas como modo de aproximação do cotidiano de uma escola ou de cursos de licenciaturas em artes visuais são alguns dos temas que nos inquietam e através dos quais temos produzido algumas experimentações. A cada nova pesquisa, temos ousado um pouco mais ou aprofundado nossas experiências. O que, por exemplo, residências artísticas (ou educacionais) em diferentes universidades, que contam com cursos de $\begin{array}{llllll}\text { (c) ETD- Educação Temática Digital } & \text { Campinas, SP } & \text { v.21 } & \text { n.2 } & \text { p.479-494 } & \text { abr./jun.2019 }\end{array}$ 
licenciatura em artes visuais, ou em uma escola pública de educação básica podem dizer às nossas inquietações sobre arte, educação e docência? Como as imagens que povoam nossos trabalhos podem adquirir um caráter menos ilustrativo, e dizer, por elas mesmas, que não são apêndices ou anexos, mas a própria pesquisa? Que efeitos nossas pesquisas e elucubrações teóricas e metodológicas podem exercer sobre as práticas pedagógicas experienciadas na educação básica e na formação docente? Não sabemos todas essas respostas, mas estamos aprendendo a experimentar algumas.

\subsection{Delírios e heterotopias em pesquisa}

Queremos, como diz o poeta, fazer os verbos delirarem. Ambicionamos, como nos instigou o filósofo, nos inquietar com heterotopias. Mais do que qualquer lirismo fácil ou sedutor, desejamos que a pesquisa que fazemos no âmbito da educação, contaminada e comprometida com uma atitude estética e artística, tenha repercussões no que acontece na educação básica desse imenso país que se chama Brasil. Nossas pesquisas partem de um lugar específico: uma faculdade de educação de uma universidade pública. É deste lugar do qual lançamos nosso olhar para as artes, e do qual queremos intervir na formação de docentes para a educação básica. Em meio a crises políticas, econômicas e morais que assolam nosso país, a nossa responsabilidade é ampliada. Enquanto as gramáticas educacionais se enchem de tentativas de controle e cerceamento de pensamento, o nosso compromisso é resistir, é rememorar a condição inerente do ser humano para a criação e a invenção na esfera da produção de conhecimento. Mais do que nunca, nossas tarefas de educar e pesquisar não podem prescindir da arte, essa inquietante aventura humana da qual não abrimos mão.

\section{REFERÊNCIAS}

BELLO, Oscar Yecid Bello. De la experiencia fotográfica a los espacios extracurriculares: otros modos para pensar la educación y el arte entre Brasil y Colombia. 2016. Dissertação (Mestrado em Educação) - Universidade Federal do Rio Grande do Sul, Porto Alegre, RS, 2016.

BREMM, Alessandra Baldissarelli. Habitar a escola: minúcias de encontros entre arte e educação. Dissertação (Mestrado em Educação) - Universidade Federal do Rio Grande do Sul, Porto Alegre, RS, 2017.

CANCLINI, Néstor García. A sociedade sem relato: antropologia e estética da iminência. São Paulo: EDUSP, 2012.

CAPRA, Carmen Lúcia. Problematizações sobre a política da arte nas licenciaturas. É preciso gostar da arte de outro jeito, a licenciatura é uma praça. 2017. Tese (Doutorado em Educação) - Universidade Federal do Rio Grande do Sul, Porto Alegre, RS, 2017.

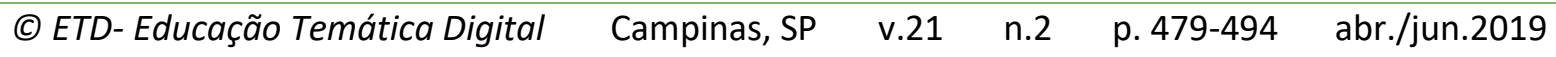


COSTA, Vanessa Priscila da. Avaliação no ensino de artes visuais: desdobramentos e implicações para a docência. 2015. Dissertação (Mestrado em Educação) - Dissertação (Mestrado em Educação) - Universidade Federal do Rio Grande do Sul, Porto Alegre, RS, 2015.

CULT. Dossiê arte sob coerção: moralismo privado no espaço público. São Paulo: Bregantini, n. 230, ano 20, dezembro 2017.

DE DUVE, Thierry. Cinco reflexões sobre o julgamento estético, Revista Porto Arte, Porto Alegre, v. 16, n. 27, p. 43-65, nov. 2009.

DIAS, Belidson, IRWIN, Rita (Orgs.). Pesquisa educacional baseada em arte: a/r/tografia. Santa Maria: UFSM, 2013.

FISCHER, Deborah Vier. Escola, artistas e docentes em movimento: encontros entre arte contemporânea e educação. Dissertação (Mestrado em Educação) - Universidade Federal do Rio Grande do Sul, Porto Alegre, RS, 2014.

FISCHER, Rosa Maria Bueno. Arte, pensamento e criação de si em Foucault: breve ensaio. Currículo sem fronteiras, v. 15, n. 3, p. 945-955, set./dez. 2015. Disponível em: http://www.curriculosemfronteiras.org/vol15iss3articles/fischer.pdf Acesso em: $11 \mathrm{dez.}$ 2017.

FISCHER, Rosa Maria Bueno. Foucault revoluciona a pesquisa em educação? In: FISCHER, Rosa Maria Bueno. Trabalhar com Foucault: arqueologia de uma paixão. Belo Horizonte: Autêntica, 2012. p. 99-112.

FONTCUBERTA, Joan. O beijo de Judas. Fotografia e verdade. Barcelona: Gustavo Gill, 2010.

FOUCAULT, Michel. O corpo utópico, as heterotopias. São Paulo: n-1 Edições, 2013.

FOUCAULT, Michel. Uma introdução a uma vida não fascista. In: FOUCAULT, Michel. Por uma vida não-fascista (Coletânea Michel Foucault Sabotagem). Coletivo Sabotagem, 2004. Disponível em: https://cesarmangolin.files.wordpress.com/2011/08/foucault-por-uma-vidanao-facista-pdf.pdf Acesso em: 07 jan. 2018.

FOUCAULT, Michel. A verdade e as formas jurídicas. Nau: Rio de Janeiro, 2003.

FOUCAULT, Michel. As palavras e as coisas. São Paulo: Martins Fontes, 2012.

FOUCAULT, Michel. Nietzsche, a genealogia e a história. In: FOUCAULT, Michel. Microfísica do poder. Rio de Janeiro: Graal, 2001. p. 15-37.

GALLO, Silvio. Pensar a escola com Foucault: além da sombra da vigilância. In: CARVALHO, Alexandre Filordi de; GALLO, Silvio. (Org.). Repensar a educação: 40 anos após Vigiar e Punir. São Paulo: Livraria da Física, 2015, p. 427-449.

$\begin{array}{llllll}\text { (C) ETD- Educação Temática Digital } & \text { Campinas, SP } & \text { v.21 } & \text { n.2 } & \text { p.479-494 } & \text { abr./jun.2019 }\end{array}$ 
HERNÁNDEZ, Fernando Hernández. A pesquisa baseada nas artes: propostas para repensar a pesquisa educativa. In: DIAS, Belidson, IRWIN, Rita L (Orgs.) Pesquisa educacional baseada em arte: a/r/tografia. Santa Maria, RS: UFSM, 2013. p. 39-61.

JAGODZINSKI, Jan, WALLIN, Jason. Arts-based research: a critique and a proposal. Rotterdam: Sense Publishers, 2013.

LOPONTE, Luciana Gruppelli. Tudo isso que chamamos de formação estética: ressonâncias para a docência. Revista Brasileira de Educação, v. 22, n. 69, abr./jun. 2017. Disponível em: http://www.scielo.br/pdf/rbedu/v22n69/1413-2478-rbedu-22-69-0429.pdf Acesso em: 07 jan. 2018.

LOPONTE, Luciana Gruppelli. Arte para a docência: estética e criação para a formação docente. Arquivos analíticos de políticas educativas, v. 21, n. 25, mar. 2013. Disponível em: https://epaa.asu.edu/ojs/article/view/1145/1083 Acesso em: 07 jan. 2018.

LOPONTE, Luciana Gruppelli. Desafios da arte contemporânea para a educação: práticas e políticas. Arquivos analíticos de políticas educativas, v. 20, n. 42, dez. 2012. Disponível em: https://epaa.asu.edu/ojs/article/view/1125/1025 Acesso em: 17 jun. 2016.

MACHADO, Roberto. Nietzsche e a verdade. São Paulo: Graal, 2002.

MOSÉ, Viviane. O homem que sabe: do homo sapiens à crise da razão. Rio de Janeiro: Civilização Brasileira, 2011.

MOSÉ, Viviane. Nietzsche e a grande política da linguagem. Rio de Janeiro: Civilização Brasileira: Rio de Janeiro, 2005.

MARTON, Scarlet. Novas liras para novas canções. In: MARTON, Scarlet. Nietzsche, seus leitores e suas leituras. São Paulo: Barcarolla, 2010.

NIETZSCHE, Friederich. Sobre verdade e mentira no sentido extra-moral. In: NIETZSCHE, Friederich. Obras incompletas. São Paulo: Editora 34, 2014.

NIETZSCHE, Friederich. A Gaia Ciência. São Paulo: Companhia das Letras, 2001.

ORDINE, Nuccio. A utilidade do inútil: um manifesto. Rio de Janeiro: Zahar, 2016.

VEYNE, Paul. Foucault: seu pensamento, sua pessoa. Rio de Janeiro: Civilização Brasileira, 2011.

VIADEL, Ricardo Marín. La 'investigacion educativa basada en las artes visuales' o 'arteinvestigacion educativa'. In: VIADEL, Ricardo Marín (Ed.). Investigación en Educación Artística. Granada: Universidad de Granada, 2006. p. 223-274.

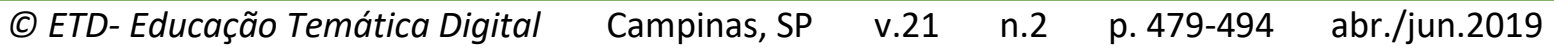


VOLZ, Jochen. Jornadas espirais: incerteza viva. In: VOLZ, Jochen, REBOUÇAS, Júlia (Orgs.). 32a Bienal de São Paulo: Incerteza Viva: Catálogo. São Paulo: Fundação Bienal de São Paulo, 2016. p. 21-27.

ROLDÁN, Joaquín, VIADEL, Ricardo Marín. Metodologias artísticas de investigación en educación. Málaga: Aljibe, 2012.

STORCK, Karine. Como viver na escola: relações entre arte, educação e docência. 2015. Dissertação (Mestrado em Educação) - Universidade Federal do Rio Grande do Sul, Porto Alegre, RS, 2015.

Revisão gramatical realizada por:

Tiago Martins de Morais

E-mail: tg.martins@gmail.com 